\title{
The Fine Structure of Intercellular Substances and Rounded Cells in the Incisor Pulp of the Guinea Pig '
}

\author{
SEONG S. HAN AND JAMES K. AVERY \\ University of Michigan School of Dentistry, Ann Arbor, Michigan
}

\begin{abstract}
The fine structure of intercellular substances and rounded cells of the incisor dental pulp of guinea pigs is described. The extracellular fibrils are of two kinds; collagen with typical cross-striations, varying from 400-700 A in diameter, and fine fibrils of 100-120 $\AA$ in diameter. In cross section the latter fibrils appeared to be composed of three or four smaller subunits of less than $50 \AA$ in diameter. The collagen fibril in the dental pulp appear singly or in small bundles of about a dozen or more fibrils. The fine fibrils are often aggregated along the cell surface.

The ground substances are finely granular to fibrillar and show localized clumping which is related to fibrillar elements. The ground substances form an incomplete covering of $200 \AA$ or more in thickness surrounuding collagen fibrils. When the collagen fibrils make a bundle, the sheath of grouund substances around one fibril becomes fused with that of adjacent fibrils.

Rounded cells including macrophages, lymphocytes and eosinophils are present in the pulp. The fine structure of these cells is similar to that found in the same types of cells previously observed in other organs.
\end{abstract}

Since the early descriptions on the periodic structure of collagen fibrils numerous authors have confirmed their characteristic cross-striations in a wide variety of connective tissues. More recently the chemical nature of connective tissue ground substances has received an increased attention, and certain biosynthetic pathways have been illuminated (Dorfman, '63). Less certain is the relationship between the collagen fibrils and ground substances.

With respect to the dental pulp, descriptions on the fine structure of extracellular substances and cellular elements other than fibroblasts have been sporadic and incidental.

This article describes and discusses the ultrastructural characteristics of intercellular substances and rounded cells of the dental pulp of guinea pig incisors. Emphasis is placed on (1) the comparison of the structure of various fibrillar elements, (2) the relationship between the extracellular fibrils and ground substances, and (3) the fine structure of macrophages and related cells.

\section{MATERIALS AND METHODS}

Twenty guinea pigs with an average body weight of $250 \mathrm{gm}$ were used. Under ether anaesthesia mandibles were rapidly dissected out and bisected through the midline. Using a pair of shears the body of the mandible was clipped off along the lateral aspect of the base from the angle forward and the entire incisor, including the growing end, was exposed. Then the tooth was removed from the mandible and briefly dipped in the fixative. The partially calcified dentin from the proximal portion was separated from the pulp, which in turn was removed from the hard shell of dentin by gently pulling with jewler's forceps.

The pulp was cut into small pieces approximately $1 \mathrm{~mm}^{3}$ in size and fixed in $6.5 \%$ glutaraldehyde buffered with $\mathrm{M} / 10$ phosphate at pH 7.4 for an hour. Following fixation the tissues were briefly rinsed in the same buffer and postfixed in $2 \%$ $\mathrm{OsO}_{4}$ at $4^{\circ} \mathrm{C}$. Again the buffer was $\mathrm{M} / 10$ phosphate at $\mathrm{pH} 7.4$ with sucrose being added to make a final concentration of $4.5 \%$ (Caulfield, '57). Some of the tissues were fixed directly in $2 \% \quad \mathrm{OsO}_{4}$ without prior fixation in glutaraldehyde. The fixed tissues were dehydrated through a graded series of ethanol, infiltrated with a mixture of epoxy resin and polymerized at

1 This investigation was supported in part by a grant from the United States Public Health Service (D-1620). 
progressively higher temperatures. The cured blocs were left in the oven for two weeks at $60^{\circ} \mathrm{C}$. Sections were made on a Porter-Blum or LKB ultramicrotome and picked up on formvar-coated grids reinforced with a thin layer of carbon. Staining of the sections was done by floating the grids on saturated uranyl acetate for two hours and $0.1 \%$ phosphotungstic acid for 30 minutes in a moisture chamber. $\mathrm{Ob}$ servations were made in a Hitachi HU-11 electron microscope.

\section{OBSERVATIONS}

Extracellular fibrils. Extracellular fibrils of the dental pulp may be catergorized into two groups: collagen and fine fibrils of 100-120 $\AA$ in diameter. The collagen fibrils were so identified by the presence of the characteristic cross-striations. Their diameter was variable, ranging from $400 \AA$ to $700 \AA$ or more (figs. $1,3,4$ and 5 ). Sometimes they appeared singly but more often they formed small bundles composed of from several to a few dozen fibrils (figs. 2 and 4). At no time were there found any heavy fiber bundles as might be seen in other types of connective tissues. The fibril bundles were located both near and away from the surface of various cells. They were present in greater numbers around the blood vessels than in the rest of the pulp.

Contrary to variations in diameter of collagen fibrils, the fine extracellular fibrils had a remarkably uniform diameter which ranged between $100 \AA$ and $120 \AA$ (figs. 3 and 5). In cross section they appeared to be composed of three or four finer subunits which measured about $50 \AA$ or less, being somewhat smaller than the intracellular fine fibrils (fig. 3). In longitudinal section occasional beading was observed with some difficulty (fig. 5). At certain points these fine fibrils appeared to be continuous with collagen fibrils. They often formed bundles aggregating near the surface of fibroblasts (fig. 3), whereas many singular ones were more or less evenly distributed throughout the intercellular space (figs. 1 and 4).

Ground substances. In tissues fixed with glutaraldehyde most of the intercellular space was filled by finely granular to fibrillar ground substances which ap- peared to clump, leaving clear spaces between the aggregates (figs. 1 and 4). These aggregates were present in close association with the extracellular fibrils. They seemed to form an incomplete covering of $200 \AA$ or more in thickness around each collagen fibril. When collagen fibrils formed a bundle, the sheaths of ground substances surrounding individual collagen fibrils became fused and the fibrils were separated only by the ground substances which seemed to cement them together.

Ground substances were also often aggregated around the fine fibrils (100$120 \bar{A}$ ). Dense flocculant materials, which did not differ in appearance from the ground substances, were occasionally found along the surface of cells (fig. 1). The appearance of the ground substances was less clear in tissues fixed with osmic acid alone.

Rounded cells. Macrophages, small lymphocytes and eosinophils were found between fibrillar elements, the macrophage being found most frequently. The cell generally had a rounded outline (fig. 6). Ruffling of the surface plasma membrane, as well as invaginations were often observed. Sometimes the ruffled projections of the membrane produced interdigitations of considerable complexity (fig. 8). Within the cytoplasm were varying numbers of round to elongated mitochondria, short flat profiles of the rough-surfaced endoplasmic reticulum, aggregates of free ribosomes and Golgi apparatus (figs. 6 through 9 ). The Golgi apparatus of the cell was located near the nucleus and was composed of stacks of short and long lamellar elements and some vesicles (fig. 7). The ground cytoplasm was of moderate density. The nucleus was fairly dense with a pronounced peripheral condensation of the chromatin (figs. 6 and 8 ). The nucleolus, when present, was small and assumed an eccentric position. The unique feature of the cytoplasm of macrophages was the presence of numerous vesicles, vacuoles and dense irregular bodies presumed to have been phagocytized (figs. 6, 7 and 9 ). The vesicles measured $60 \mathrm{~m} \mu$ or more in diameter, while the vacuoles showed a great variation in both diameter and shape. The interior of the vesicles and 
vacuoles was clear and often less electrondense than the ground cytoplasm. The phagocytized bodies were also variable in size and appearance, exhibiting an interior of extreme heterogeneity,

Both eosinophils and lymphocytes were found occasionally. In general they were located in the apical two thirds of the pulp. The eosinophil could be so identified on the basis of its characteristic granules and the appearance of its nucleus. Most of the lymphocytes were of small size and their cytoplasm contained only a few small mitochondria, vesicles, etc. (fig. 10). There was no notable difference in structure of these blood elements from that the cells in peripheral blood and lymphoid organs described previously.

Around the arteriolar ends and capillary pericytes, with an intracellular structure resembling that of the fibroblast, were observed (fig. 11). Along the surface of pericytes were numerous collagen fibrils which often were intermittently separated by a thin layer of electron-dense materials simulating the appearance of the basement membrane (fig. 11, arrow). In addition a small number of unmyelinated nerve fibers were present near the blood vessels (fig. 2),

\section{DISCUSSIONS}

Extracellular fibrils. A number of recent reviews provide a comprehensive coverage of our current understanding of the chemical and structural characteristics of collagen and its formation (Chapman, '62; Gould, '63; Lowther, '63; Porter, '64; and Robertson, '64). Within the fibroblast peptide subunits of 30,000 molecular weight, being composed of about 250 amino acids, are assembled on the ribosome, and then carbohydrates of unknown composition are added to aspartic acid residues at one end of the peptide and serve to link it with another peptide. Thus, alpha chains each containing four of these peptides and having a molecular weight of 120,000 are formed. Three of the alpha chains become associated to form the typical coiled structure of tropocollagen with a molecular weight of 360,000 . Whether this last step is an intracellular or extracellular event remains to be seen, although there are evidences that fibril formation may proceed, in certain cases, within the
Golgi apparatus until recognizable collagen fibrils are formed (Sheldon and Kimball, '62; Han et al., '64). The insoluble collagen fibril is produced extracellularly by gradual development of stronger bonds between subunits, making beta and gamma components, a change attributed to aging of the fibers. Structurally, the fact that the tropocollagen molecule is a rigid rod about $2,800 \AA$ long and $14 \AA$ in diameter has been clarified (Boedtker and Doty, '55 and '56; Hall, '56; and Hall and Doty, '58). The polymerization of tropocollagen molecules under normal conditions is facilitated by longitudinal side-byside registration of the molecules in a quarter-stagger pattern, hence the production of typical $640 \AA$ cross-striations.

The importance of the fibroblast surface in initial polymerization of monomeric molecules has been recognized (Sterns, '40a and b) and emphasized repeatedly (Porter, '51; Godman and Porter, '50; and Yardley et al., '60). Irrespective of whether the "primary fbrils" ${ }^{2}$ are collagen or not, it appears to be a general consensus that fine extracellular fibrils measuring about $100 \AA$ in diameter are observed along the outside of the plasma membrane, and that these fibrils are brought and cemented together to form collagen fibrils. As evidence for the claim that $100 \AA$ fibrils are building blocs of larger collagen fibers the periodic beading of the fibrils similar to that of collagen has been observed by previous workers (Chapman, '62; and Fernando and Movat, '63) and also noted in this study.

The subunit structure observed by us in cross-sections of these fine fibrils seems to have not been recognized previously. The subunit structure is still much too big to be a cross-section of a tropocollagen molecule and, therefore, the observation suggests that these subunits are finer fibrils which constitute the $100 \AA$ fibrils. The reason one fails to recognize a host of fibrils having a range of different diameters rather than two types of fibrils, if the progressive accretion of unit fibrils were to produce mature collagen, could

2 The term "primary fibrils" is used by Porter ("64) to designate the earliest fibrils which are formed by "the cell surface or the cortex beneath the surface," and are supposed to "increase greatly in diameter by accretion of soluble collagen on their surfaces." 
not be secured from available information. The possible and tempting inference would be that there might be a fundamental physicochemical difference between the primary fibrils ${ }^{3}$ that produce the fine fibrils of $100 \AA$ in diameter from those that serve as sites of nucleation for regular collagen fibrils. Thus the two distinctly different fibril species so produced might be independent of each other in terms of polymerization behavior. In fact the random and abundant distribution of the fine fibrils in the dental pulp has no apparant relation with that of collagen fibrils. This does not necessarily contradict the concept that the fine fibrils produce collagen fibrils in the immediate vicinity of the fibroblast, since such primary fibrils are presumably formed under an intimate control of fibroblastic activities (Porter, '64) and, therefore, could conceivably be modified after their formation inducing further polymerization of the fine fibrils. Karrer (' 60 ), in a study of developing aortae of chick embryos, also recognized the fine fibrils as a regular extracellular component of the connective tissue and described their "independence" from collagen.

The appearance of ground substances. The structural identity of the connective tissue ground substances has received a rather limited attention in the past, although Flemming, as early as 1876 , recognized and described it as a substance which supposedly was binding collagen fibers to form bundles, the Kittsubstanz (1876). For a period following Flemmings' statement the lack of appropriate techniques in early days for its histological demonstration produced some doubts about the existance of such a substance (Curran, '61). More recently, improvements in staining as well as biochemical techniques have revealed that the substance consisted of acid and neutral mucopolysaccharides, non-callagenous protein, a variety of small molecules and water, and much of the biosynthetic pathways of large polysaccharides has been made clear (Dorfman, '63; and Strominger, '64). Despite attempts to characterize the structure, the ground substance is still described as "amorphous" and the use of electron microscopes has been of little help in clarifying its structure.
Without regard to the ambiguous state of knowledge on the structure of the ground substance the importance of its constituents in the maintenance of biochemical functioning of the connective tissue has been emphasized both by the chemists (Dorfman, '63; Muir, '61; Mark, '64; and Katchalsky, '64) and morphologists (Bennett, '63). Since polyelectrolytes of the connective tissue are electrically charged polymers, their properties are determined by the interplay of electrical forces, the Brownian motion of the macromolecular chain and Van der Waals forces (Katchalsky, '64). For instance, an increase in viscosity can be brought forth by charged polyacids or polybases that become stretched by electrostatic forces, and a decrease of osmotic pressure may be facilitated by the attraction of counterions by the electric field of polyions. Furthermore, it is reasonable to think that such electric interplay may also be operative between the charged surface of formed fibrils and soluble macromolecules. Indeed it is possible that the fibrillar elements might serve as nucleating sites for the precipitation of macromolecules which would occur at the point of polymeric electroneutrality. The intimate structural relationship between formed fibrils (both collagen and fine fibrils) and the ground substance, as observed in glutaraldehyde fixed specimens of this study, might be regarded as a morphological support for considerations given above. The clear space separating cloudy masses might represent an exageration due to fixation artifact.

Comments on cells with defensive potency. The presence in the dental pulp of blood elements and macrophages concerned with the defensive mechanisms has been noted by light microscopy (Orban, '57), and pathological behavior of these cells has been documented (Thoma, '54). This study confirms the identity of these cells at the electron microscopic level.

One of the characteristics of the macrophage cytoplasm is the presence of numerous vesicles and vacuoles which are thought to be related to pinocytic and phagocytic activities of the cell (Palade, '55 and '56; Karrer, '60; and Han, '61).

\footnotetext{
3 See footnote 2.
} 
In agreement with this general contention the cytoplasm of pulual macrophages also contains numerous cytoplasmic vesicles, vacuoles and foreign bodies presumed ingested. Little information is available regarding the origin of membranes that produce vesicles and vacuoles. Bennett ('56) advanced the membrane flow theory which illustrates the process of vesicle formation but fails to explain the initial formation of membranes that are used in the "flow."

The fine structure of pericytes (Rouget's cells), as observed in the dental pulp of hamster incisors, has been previously described and discussed in some detail (Han and Avery, '63). The perivascular cell of the guinea pig dental pulp is identical in location and in structure to that observed in the hamster pulp.

\section{LITERA'TURE CITED}

Bennett, H. S. 1956 The concept of membrane flow and membrane vesiculation as mechanisms for active transport and ion pumping. J. Biophys. Biochem. Cytol., 2 (no. 4, suppl.): 99-103.

1963 Morphological aspects of extracellular polysaccharides. J. Histochem. Cytochem., 11: 14-23.

Boedtker, H., and P. Doty 1955 On the nature of the structural element of collagen. J. Am. Chem. Soc., 77: 248-249.

1956 The native and denatured states of soluble collagen. J. Am. Chem. Soc., 78: 4267-4280.

Caulfield, J. B. 1957 Effects of varying vehicle for $\mathrm{OsO}_{4}$ in tissue fixation. J. Biophys. Biochem. Cytol., 3: 827-830.

Chapman, J. A. 1962 Fibroblasts and collagen. Brit. Med. Bull., 18: 233-237.

Curran, R. C. 1961 The histological demonstration of connective tissue mucopolysaccharides. In: The Biochemistry of Mucopolysaccharides of Connective Tissue. Biochem. Soc. Symp. No. 20. F. Clark and J. K. Grant, eds., Cambridge University Press, pp. 24-38.

Dorfman, A. 1963 Polysaccharides of connective tissue. J. Histochem. Cytochem., 11: 2-13.

Fernando, N. V. P., and H. F. Movat 1963 Fibrillogenesis in regenerating tendon. Lab. Invest., 12: 214-229.

Flemming, W. 1876 Beitrage zur Anatomie und Physiologie des Bindesgewebes I. Vom Bau des lockeren Interstitialgewebes. Arch. mikr. Anat., 12: $361-433$.

Godman, G. C., and K. R. Porter 1960 Chondrogenesis, studied with the electron microscope. J. Biophys. Biochem. Cytol., 8: 719-760.

Gould, B. S. 1963 Collagen formation and fibrogenesis with special reference to the role of ascorbic acid. Internatl. Rev. Cytol, 15: 301361.
Hall, C. E. 1956 Visualization of individual macromolecules with the electron microscope. Proc. Nat. Acad. Sci., Wash., 42: 801-806.

Hall, C. E., and P. Doty 1958 A comparison between the dimensions of some macromolecules determined by electron microscopy and by physical chemical methods. J. Am. Chem. Soc., 80: 269-1274.

Han, S. S. 1961 The ultrastructure of the mesenteric lymph node of the rat. Am. J. Anat., 109: 183-226.

Han, S. S., and J. K. Avery 1963 The ultrastructure of capillaries and arterioles of the hamster dental pulp. Anat. Rec., 145: 549-572.

Han, S. S., J. K. Avery and L. E. Hale 1964 The fine structure of differentiating fibroblasts in the incisor pulp of the guinea pig. Submitted for publication.

Karrer, H. E. 1960 Electron microscopic study of the phagocytosis process in the lung. $J$. Biophys. Biochem. Cytol., 7: 357-366.

- 1960 Electron microscope study of developing chick embryo aorta, J. Ultrastr. Res., 4: 420-454.

Katchalsky, A. 1964 Polyelectrolytes and their biological interactions. In: Connective Tissue: Intercellular Macromolecules. Proc. Symp. spons. by N. Y. Heart Assoc., Little, Brown and Co., Boston. pp. 9-42.

Lowther, D. A. 1963 Chemical aspects of collagen fibrillogenesis. In: InternatI. Rev. Conn. Tissue Res., Vol. II. D. A. Hall, ed., Acad. Press. New York and London. pp. 64-126.

Mark, H. 1964 Macromolecules: origin, development, significance. In: Connective Tissue: Intercellular Molecules. Proc. Symp. spons. by N. Y. Heart Assoc. Little, Brown and Co., Boston. pp. 5-8.

Muir, H. 1961 Chondroitin sulphates and sulphated polysaccharides of connective tissue. In: The Biochemistry of Mucopolysaccharides of Connective Tissue. Biochem. Soc. Symp. No. 20. F. Clark and J. K. Grant, ed., Cambridge University Press. pp. 4-22.

Orban, B. J. 1957 Oral Histology and Embryology. Fourth edition. C. V. Mosby Co., pp. 143-150.

Palade, G. E. 1955 Relations between the endoplasmic reticulum and the plasma membrane in macrophages. Anat. Rec., 121: 445 (Abstract).

1956 The endoplasmic reticulum. J Biophys. Biochem. Cytol., 2 (No. 4, suppl.): 85-98.

Porter, K. R. 1951 Repair process in connective tissues. In: Connective Tissues. Transactions of the Third Conference. C. Ragan, ed., Josiah Macy, Jr. Foundation. Packanack Lake, New Jersey.

1964 Cell fine structure and biosynthesis of intercellular macromolecules. In: Connective Tissue: Intercellular Macromolecules. Proc. Symp. spons. by N. Y. Heart Assoc., Little, Brown and Co., Boston. pp. 167-196.

Robertson, W. Van B. 1964 Metabolism of collagen in mammalian tissues. In: Connective 
Tissue: Intercellular Macromolecules. Proc. Symp. spons. by N. Y. Heart Assoc., Little, Brown and Co., Boston. pp. 93-106.

Sheldon, H., and F. B. Kimball 1962 Studies on cartilage III. The occurrence of collagen within vacuoles of the Golgi apparatus. J. Cell Biol., 12: 599-614.

Stearns, M. L. 1940a Studies on the development of connective tissue in transparent chambers in the rabbits' ear. Part I, Am. J. Anat., 66: $133-176$.

1940b Studies on the development of connective tissue in transparent chambers in the rabbits' ear. Part I., Am. J. Anat, 67: 55-97.
Strominger, J. L. 1964 Nucleatide intermediates in the biosynthesis of heteropolymeric polysaccharides. In: Connective Tissue: Intercellular Macromolecules, Proc. Symp. spons. by N. Y. Heart Assoc., Little, Brown and Co., Boston. pp. 139-153.

Szirmai, J. A. 1963 Quantitative approaches in the histochemistry of mucopolysaccharides. J. Histochem. Cytochem., 11: 24-34.

Thoma, K. H. 1954 Oral Pathology. Fourth Edition. C. V. Mosby Co., pp. 369-394.

Yandley, J. H., M. W. Heaton, L. M. Gains, Jr. and L. E. Shulman 1960 Collagen formation by fibroblasts. Johns Hopskins Hosp. Bull., 106: 381-393.

PLATE 1

EXPLANATION OF FIGURES

1 The relationship of collagen fibrils to ground substance. Several to a few dozen collagen fibrils make up a bundle which is surrounded by a dense amorphous to finely fibrillar ground substance. Elsewhere numerous fine fibrils are present. They also appear to be associated with the dense ground substances. Fixed in gutaraldehyde and osmic acid. Approximately $\times 68,000$.

2 An unmyelinated nerve fiber sectioned transversely. Note the single sheet of Schwann cell cytoplasm around the nerve fiber in which are found two mitochondria and numerous vesicles. A condensation of ground substances is noticed surrounding the Schwann cell sheath. Fixed in osmic acid. Approximately $\times 36,000$. 


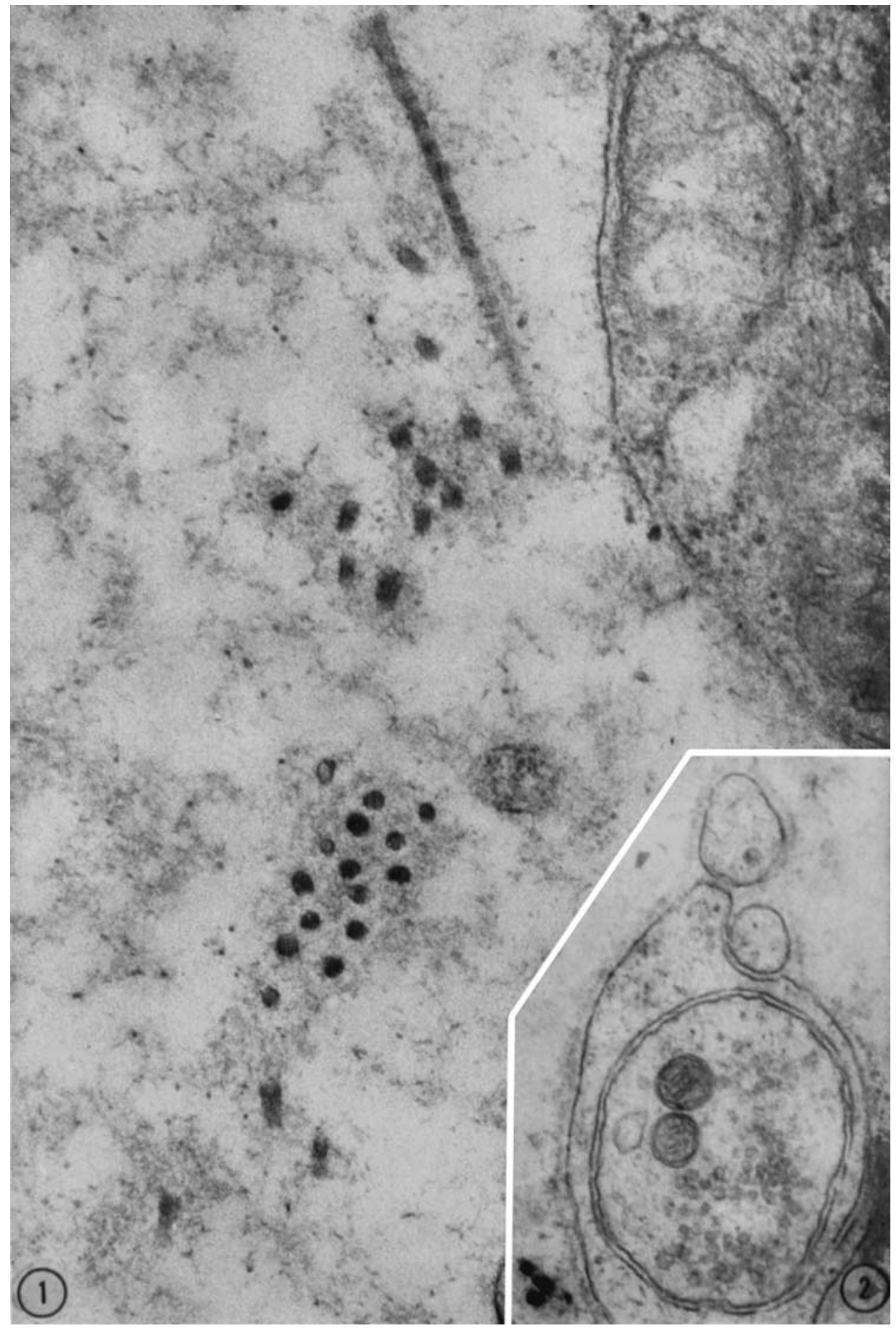




\section{PLATE 2}

EXPLANATION OF FIGURES

3 Differences in size among intracellular and extracellular fibrils are depicted in this photograph which show all three fibrils in cross section. The intracellular fibrils are the smallest, measuring $60 \AA$; the extracellular ones measure 100-120 $\AA$; and the collagen fibrils measure $400 \AA$ and up. Fixed in osmic acid. Approximately $\times 82,000$.

4 Intercellular region similar to the one found in figure 1 . Here the bundle is composed of about three dozen individual collagen fibrils. Fixed in glutaraldehyde and osmic acid. Approximately $\times 66,000$.

5 Longitudinally oriented extracellular fibrils. The collagen fibrils show the characteristic periodicity while the fine fibrils do not. Fixed in osmic acid. Approximately $\times 65,400$. 


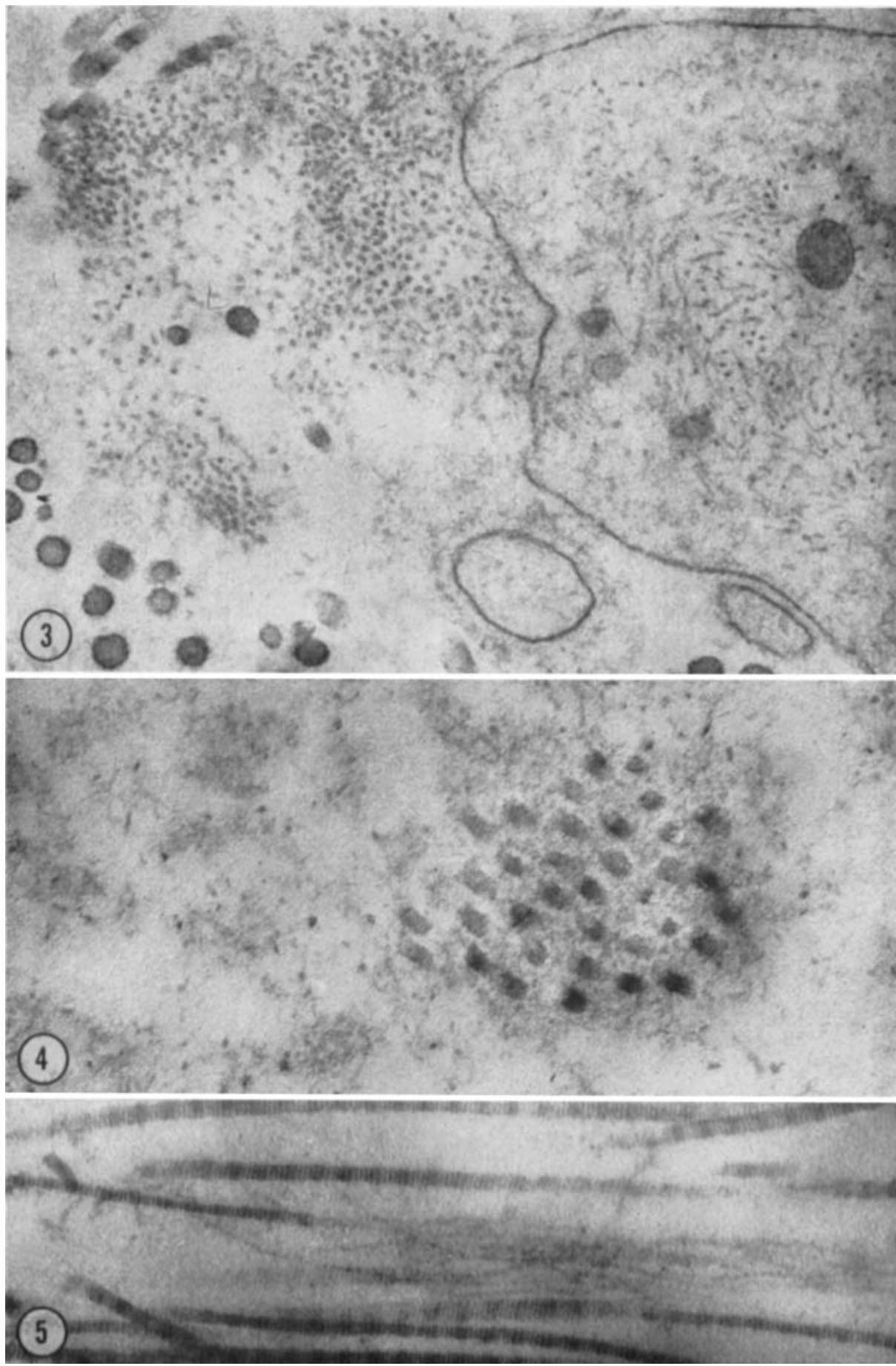


PLATE 3

EXPLANATION OF FIGURE

6 A macrophage, showing structural characteristics common to other macrophages found elsewhere in the body; namely, vacuoles and vesicles, dense irregular bodies (presumably phagocytized materials), a small number of flat profiles of the RER and a dense nucleus. Fixed in glutaraldehyde and osmic acid. Approximately $\times 13,400$. 


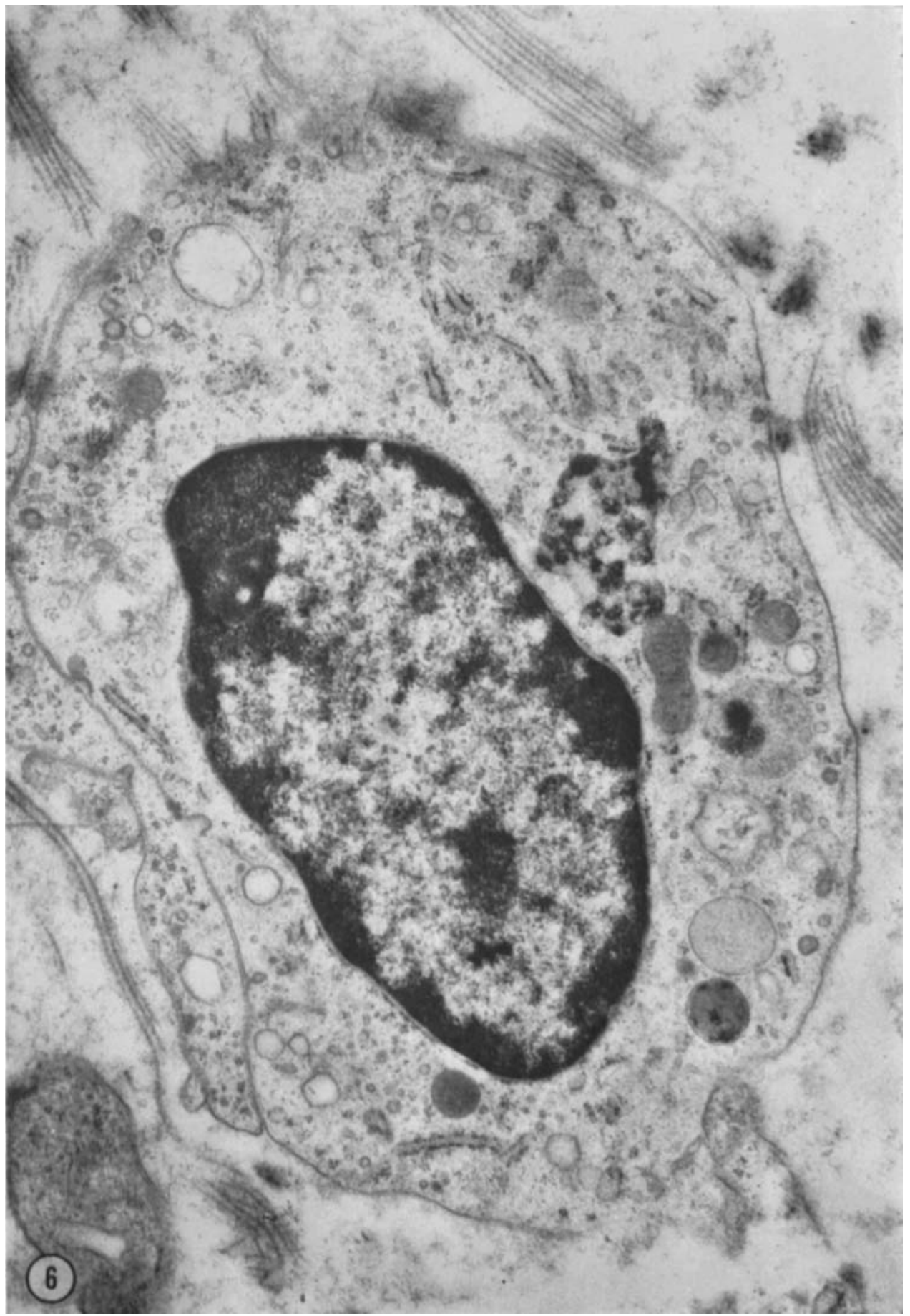




\section{PLATE 4}

EXPLANATION OF FIGURE

7 A portion of the cytoplasm of a macrophage. In addition to numerous vesicles and vacuoles, a well-developed Golgi complex is seen. The Golgi complex of a macrophage is notably free of dilated lamellar elements and associated large vacuoles. Fixed in osmic acid. Approximately $\times 34,000$. 


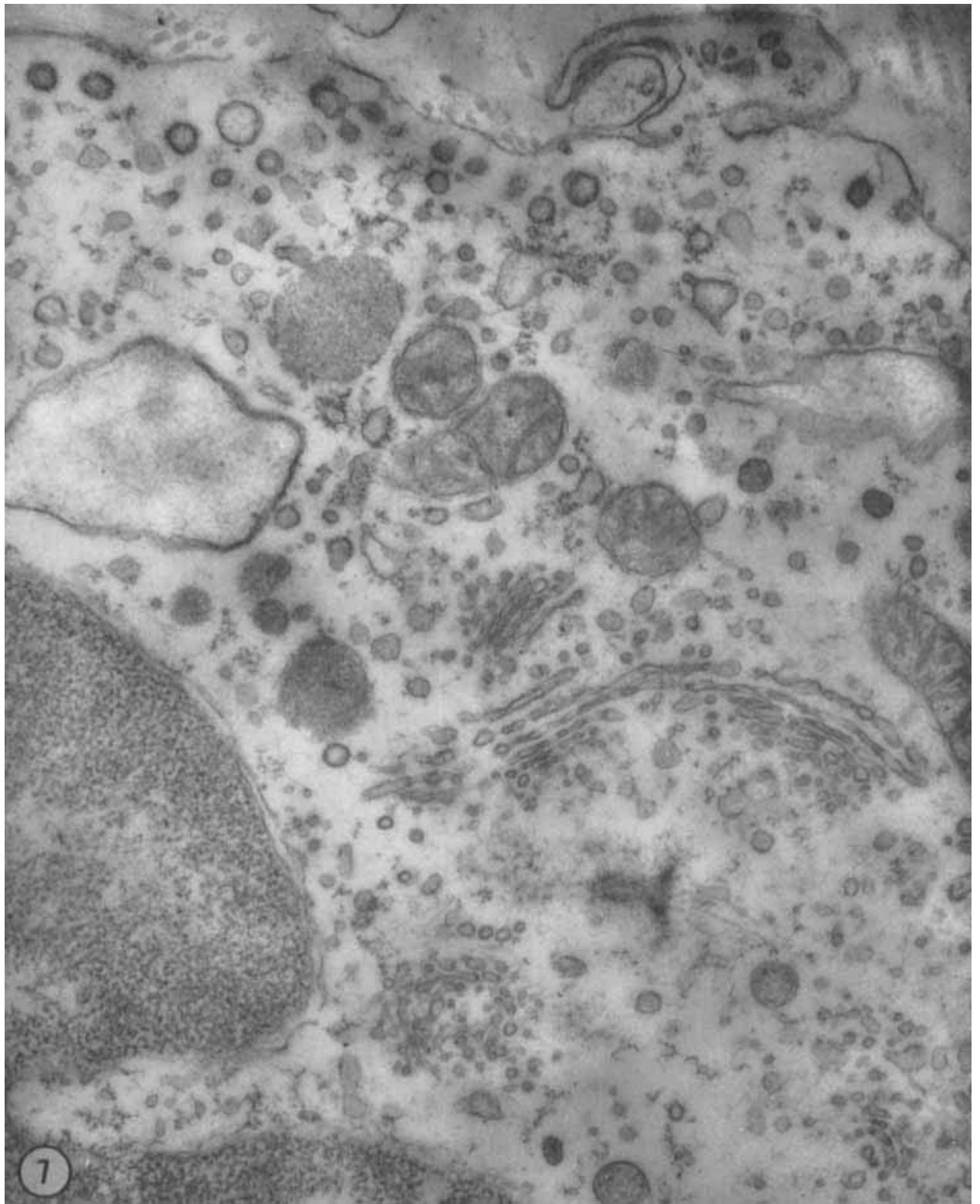


PLATE 5

EXPLANATION OF FIGURES

8 A portion of the cytoplasm of a macrophage. The pattern of interdigitation of ruffled plasma membrane is well demonstrated. Fixed in glutaraldehyde and osmic acid. Approximately $\times 53,600$.

9 A portion of the cytoplasm of a macrophage. In this micrograph details of the several phagocytized particles may be seen. Note the flat profiles of the RER as well as small vesicles. Fixed in osmic acid. Approximately $\times 52,000$. 


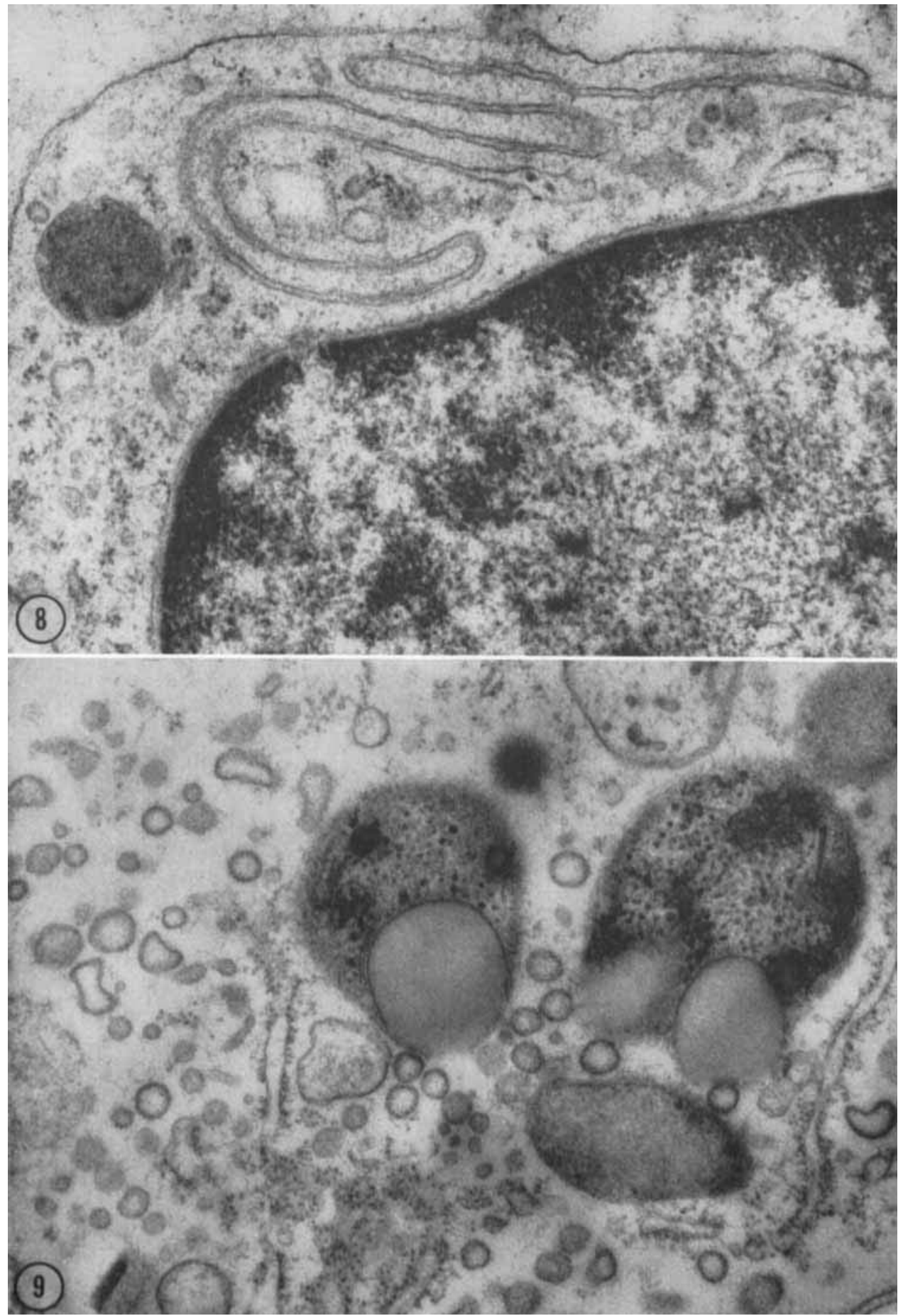


PLATE 6

EXPLANATION OF FIGURES

10 A small lymphocyte found in the pulp. Fixed in glutaraldehyde and osmic acid. Approximately $\times 10,200$.

11 A perivascular cell around a terminal arteriole. The prominence of the Golgi apparatus and the RER is often characteristic of this cell. Fixed in osmic acid. Approximately $\times 10,800$. 

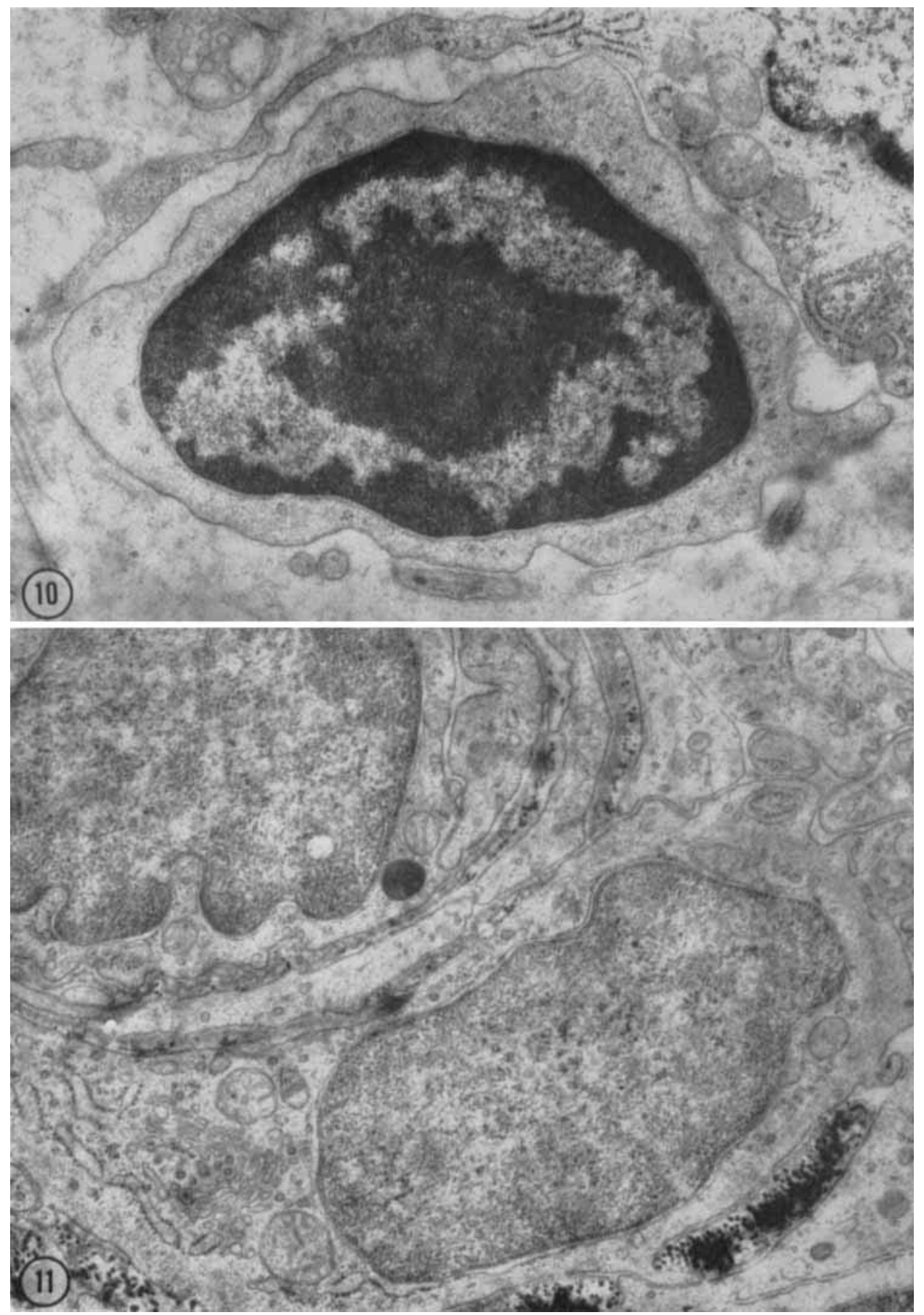